\title{
The diagnostic and prognostic value of serum endocan in patients with cirrhotic cardiomyopathy
}

\author{
ANDREI MIHAI VOIOSU ${ }^{1}$, PAUL BĂLĂNESCU ${ }^{2,3}$, IOANA DAHA $^{2,4}$, BIANCA SMARANDACHE $^{1}$, AURELIA RĂDOI $^{2}$, \\ RADU BOGDAN MATEESCU ${ }^{1,2}$, CRISTIAN RĂSVAN BĂICUŞŞ, ${ }^{2,3}$, THEODOR ALEXANDRU VOIOSU ${ }^{1,2}$ \\ ${ }^{1}$ Gastroenterology Department, "Colentina” Clinical Hospital, Bucharest, Romania \\ ${ }^{2}$ UMF "Carol Davila", Bucharest, Romania \\ ${ }^{3}$ CDPC Clinial Immunology Laboratory, "Colentina" Clinical Hospital, Bucharest, Romania \\ ${ }^{4}$ Cardiology Department, "Colentina" Clinical Hospital, Bucharest, Romania \\ ${ }^{5}$ Internal Medicine Department, "Colentina”" Clinical Hospital, Bucharest, Romania
}

\begin{abstract}
Background. We aimed to determine the relationship between endocan and cirrhotic cardiomyopathy.

Materials and methods. Patients with liver cirrhosis and no heart disease were included in a prospective observational study with liver disease decompensation and death as primary outcomes.

Results. 83 cirrhotic patients were included and 32 had cirrhotic cardiomyopathy. Endocan levels were significantly lower in patients with cirrhotic cardiomyopathy $(5.6 v s .7 \mathrm{ng} / \mathrm{mL}, \mathrm{p}=0.034)$. Endocan correlated with severity of cirrhosis, time to decompensation or death from liver disease (OR 4.5 95\% CI 1.06-31.1).

Conclusion. Endocan is a promising biomarker of severity of cirrhosis and may help in the diagnosis of cardiac dysfunction in this population.
\end{abstract}

Key words: cirrhotic cardiomyopathy; endocan; echocardiography; follow-up studies; portal hypertension; haemodynamics; cirrhosis.

\section{INTRODUCTION}

Endocan is a soluble, endothelial-derived dermatan sulfate proteoglycan implicated in inflammation and angiogenesis $[1,2]$. Formerly known as endothelial cell-specific molecule-1, endocan is synthesized by endothelial cells and secreted in serum where it performs its main function of inhibiting the migration of inflammatory cells through activated vascular endothelium. Studies have convincingly shown that endocan is involved in the mechanisms of acute inflammation and neovascularization in various pathological conditions such as sepsis $[3,4]$ and tumor progression [5] and recent data shows a role for endocan as an indicator of cardiovascular disease [6]. While its value as a diagnostic or prognostic marker for hepatocellular carcinoma is under investigation [7-9], there have been few papers on endocan in the setting of liver cirrhosis $[10,11]$.

Cirrhosis is a systemic disease characterized by a severe and progressive alteration of metabolic functions, inflammatory responses and haemodynamic parameters that leads to the development of complications that dictate patient outcome. One such complication that is still incompletely characterized is cirrhotic cardiomyopathy (CCM), a term used to define the inadequate response of the cardiac function to stress in patients with advanced liver disease [12]. Cirrhotic cardiomyopathy has been linked to haemodynamic decompensations following events such as infections, insertion of TIPS or liver transplant and may play a role in the development of hepatorenal syndrome [13]. While the exact mechanisms leading to haemodynamic dysfunction are not completely understood, studies have shown the importance of molecules such as endotoxin, tumor necrosis factor- $\alpha$ and endothelin-1 in the evolution of cirrhotic complications [14-20]. The lack of universally accepted diagnostic criteria and debate around the optimal tools and echocardiographic algorithms for diagnosing this entity represent an additional difficulty in assessing the real impact of cirrhotic cardiomyopathy. In the setting of difficult access to liver transplantation new and reliable biomarkers are needed to improve and personalize the management of cirrhotic patients who develop significant cardiovascular dysfunction. Furthermore, these potential markers need to be tested in prospective studies in order to prove a significant clinical benefit.

We aimed to investigate the relationship between endocan and the presence of cirrhotic cardiomyopathy 
and assess the prognostic role of this novel biomarker in the development of liver-related complications in a prospective follow-up cohort study.

\section{MATERIAL AND METHODS}

This is an analysis of an inception cohort of 90 consecutive patients with documented liver cirrhosis who were enrolled in an ongoing prospective observational study at our tertiary referral center [21]. Consecutive cirrhotic patients presenting at Colentina clinical Hospital were enrolled between November 2013 and May 2015 and monitored for complications at regular intervals. Patients with significant comorbidities such as severe lung disease, ischemic heart disease, valvulopathies, arterial hypertension, pulmonary hypertension, diabetes, confirmed malignancies, active infections, severe anaemia, cachexia or severe obesity, acute hepatitis and renal failure were excluded.

A thorough medical history, complete physical examination, 12-lead ECG, routine blood work and aminoterminal pro-brain natriuretic peptide (NTproBNP) measurements were recorded in all patients. Child-Pugh and Model for end-stage liver disease (MELD) scores were used to assess the severity of cirrhosis. Echocardiography was performed by a single experienced cardiologist (ID) on a iE33 ultrasonographer (Philips Medical Systems, Best, the Netherlands) with structural and functional parameters measured according to current guidelines [22]. Use of betablockers and aldosterone antagonists was noted in the study file in order to address the possibile confounding influence of medication on clinical and ultrasonographic parameters. Patients were examined while on a low-sodium diet and, where applicable, at least 48 hours after evacuatory paracentesis.

\section{Diagnosis of cirrhotic cardiomyopathy}

Cirrhotic cardiomyopathy was defined according to the 2005 Montreal consensus as systolic dysfunction (left ventricular ejection fraction $<55 \%$ ) and/or diastolic dysfunction (at least 2 out of 3 criteria: age-adjusted early-to-late peak diastolic mitral inflow velocity ratio- $\mathrm{E} / \mathrm{A}<1$, isovolumetric relaxation time of the left ventricle- IVRT $>80 \mathrm{~ms}$, deceleration time of the E wave- DT $>200 \mathrm{~ms}$ ) [12]. Left atrial volume indexed to the body-surface area (LAV) and lateral early diastolic mitral annular velocity (E') determined by tissue Doppler imaging were recorded in order to aid in the diagnosis of diastolic dysfunction of the left ventricle. A prior intermediary analysis we performed on the cohort revealed a good concordance between the definitions of cirrhotic cardiomyopathy incorporating tissue Doppler imaging and, respectively, pulsed-wave Doppler mitral parameters indicative of diastolic dysfunction [21].

In order to provide additional data on the cardiac function of the patients 12-lead ECG and NT-proBNP levels were recorded at the initial visit. The Fridericia formula $\left(\mathrm{QTc}=\mathrm{QT} / \mathrm{RR}^{0.33}\right)$ was used for calculation of rate-adjusted QT interval with a prolonged repolarization interval defined as any over $440 \mathrm{~ms}$. NT-proBNP was measured from venous blood samples with a standardized commercially available assay $\left(\right.$ Elecsys ${ }^{\circledR}$ proBNP II, Roche Diagnostics $\mathrm{GmbH}$, Mannheim) prior to echocardiography.

\section{Endocan sampling}

Serum samples were taken from all patients and refrigerated at $-80^{\circ} \mathrm{C}$. Endocan measurements were made with a commercial sandwich ELISA kit from Lunginnov $\mathbb{C}$ (Lille, France) according to the manufacturer's instructions. Briefly, samples from healthy controls were diluted two-fold and patient samples were diluted four-fold into the dilution buffer provided. The minimum level of detection of the assay was $0.132 \mathrm{ng} / \mathrm{mL}$. All samples were assayed in duplicate. The absorbance was measured at $450 \mathrm{~nm}$ on a spectrophotometer (BioRad, Hercules, CA, USA) and a 4-parameter logistic regression curve was used for standard curve fitting analysis. Results were expressed as nanograms per milliliter (ng/mL).

Serum samples from a control group of 20 healthy volunteers presenting at our clinic for screening colonoscopies were also measured for endocan levels.

\section{Follow-up}

The study included a telephonic follow-up at every 3 months up to 24 months (median 12 months) and visits at the site one year after enrollment. Liver disease-related complications (new-onset or worsening of ascites, encephalopathy, haemorrhage, severe infections including spontaneous bacterial peritonitis, hepatorenal syndrome, hepatocellular carcinoma and death) were considered relevant events and recorded at each follow-up contact. Wherever possible medical records were consulted and indepth interviews with the patients' emergency contacts were carried out. Three patients were lost to 
follow-up at various times during the study and one was transplanted during the study period with their outcomes being censored at the last recorded visit. Standard of care procedures for screening of complications including regular abdominal ultrasonography and endoscopies were carried out according to common guidelines.

\section{Statistical analysis}

Statistical analysis was performed using the SPSS 16 software (Chicago, Il, USA). Results are reported as means and standard deviations for variables with a normal distribution, and median, minimum and maximum respectively for variables with a nonnormal distribution. Univariate analysis was conducted using the Chi-square test for nominal variables, nonparametric tests for variables with nonnormal distribution (Mann Whitney U, Kruskall Wallis) and student $t$-test for variables with normal distribution. To assess the role of endocan in prognosis we performed multivariate analysis adjusting for age, gender and severity of liver disease through binary logistic regression. Comparison of time-toevent for different variables was conducted using the log-rank Mantel-Cox test and Kaplan-Meier survival curves were then created. Analysis was 2-tailed, with a $p<0.05$ considered statistically significant.

The study was approved by the local ethics committee (Colentina Hospital Ethical Committee for Clinical Research) and respected the principles of the 1975 Declaration of Helsinki. Written informed consent was obtained from each patient included in the study.

\section{RESULTS}

\section{Study population}

Two hundred and eleven patients with cirrhosis presenting at our clinic during the study enrollment period were screened and 121 met the exclusion criteria (Fig. 1). Eighty-three out of the 90 patients enrolled were included in the final analysis (in three patients echocardiography could not be performed, one was excluded due to preexisting undiagnosed ischemic heart disease, one due to severe portopulmonary hypertension and two had no serum samples for endocan measurement). The final study population was comprised of 50 men and 33 women (mean age $59 \pm 10$ years) that were followed for a total of 96.8 patient-years. The most frequent etiology of cirrhosis in the group was chronic alcohol use (33 patients), followed by chronic viral hepatitis $\mathrm{C}$ (31 patients), chronic viral hepatitis B (12 patients), mixed hepatic viral infection (5 patients) and other causes ( 2 patients). According to the Child-Turcotte classification forty-four patients were Child class A, 16 patients were Child B and 23 were Child C and the median MELD score for the cohort was 12 (range 6-27). The study population characteristics are presented in Table 1.

Table 1

Characteristics of the study population

\begin{tabular}{|l|c|}
\hline Patient characteristic $(\mathbf{n}=\mathbf{8 3})$ & 59 years $( \pm 10)$ \\
\hline Mean Age $( \pm$ SD) & $33(40 \%)$ \\
\hline Female Gender $(\%)$ & \\
\hline Etiology & 33 \\
\hline Alcohol & 31 \\
\hline Hepatitis C & 12 \\
\hline Hepatitis B & 5 \\
\hline Mixed viral infection & 2 \\
\hline Other & \\
\hline Child-Pugh class & 44 \\
\hline A & 16 \\
\hline B & 23 \\
\hline C & $12(6-27)$ \\
\hline MELD score (range) & $3.3( \pm 0.75)$ \\
\hline Albumin (g/dL) & $2.3( \pm 2.3)$ \\
\hline Bilirubin $(\mathrm{mg} / \mathrm{dL})$ & $0.76( \pm 0.23)$ \\
\hline Creatinine (mg/dL) & $149.3(12-1026)$ \\
\hline NT-proBNP (pg/mL) & $420( \pm 26)$ \\
\hline QTc (ms) & $90.1( \pm 12.3)$ \\
\hline Mean Arterial Pressure (mmHg) & $59 / 24$ \\
\hline Use of betablockers (yes/no) & $47 / 36$ \\
\hline Use of aldosterone antagonists (yes/no) & \\
\hline
\end{tabular}




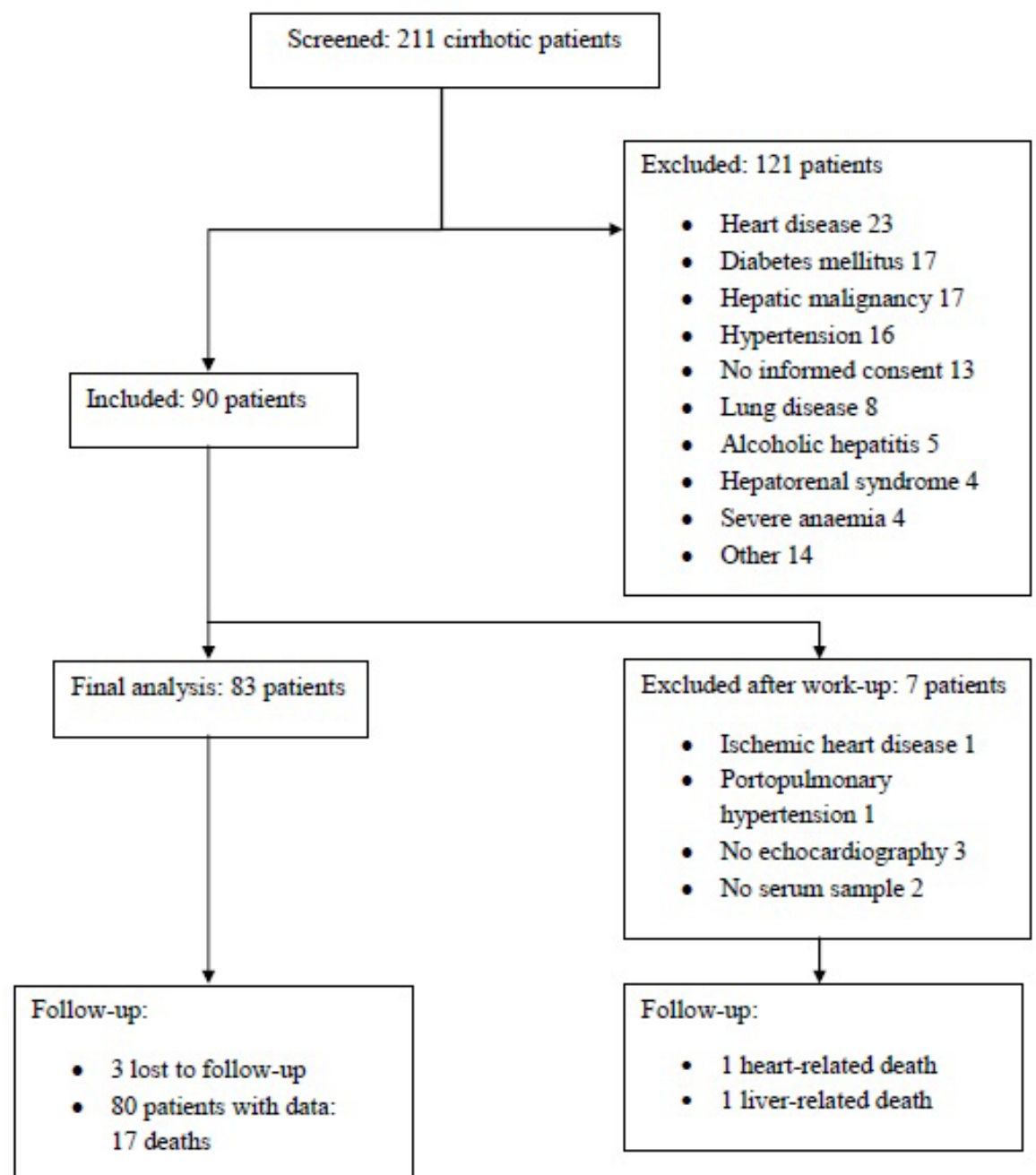

Figure 1. Flowchart of patient selection and follow-up.

\section{Endocan levels in cirrhosis}

Previous experience with endocan suggested that normal endocan levels in a healthy population are below $3 \mathrm{ng} / \mathrm{mL}[23,24]$. In order to have a comparator for the cirrhotic cohort we also measured endocan levels in a control group of 20 patients with no history of liver, lung or heart disease. The range of values in this control group was 0.44$2 \mathrm{ng} / \mathrm{mL}$ with a median value of $0.79 \mathrm{ng} / \mathrm{mL}$. Endocan levels were significantly higher in the cirrhotic cohort, with a median value of $6.7 \mathrm{ng} / \mathrm{mL}$ (range 0.9-24.3 ng/mL). Endocan levels did not vary significantly according to age, gender, creatinine levels or etiology of cirrhosis.

\section{Endocan and cirrhotic cardiomyopathy}

According to the Montreal criteria [12] thirtytwo patients had diastolic and/or systolic dysfunction and were diagnosed with cirrhotic cardiomyopathy (Table 2). Two patients had an inadequate ultrasonographic window and were not included in the analysis due to unreliable measurement of heart function parameters. Gender, age or etiology of liver disease did not correlate with the presence or absence of cirrhotic cardiomyopathy. Severity of liver disease did not influence the distribution of cirrhotic cardiomyopathy as 19 of the 43 patients with compensated (Child class A) and 13 of the 38 with decompensated cirrhosis (Child class B or C) had cirrhotic cardiomyopathy. The numbers of patients taking drugs that could influence study biomarkers or outcome, such as betablockers or aldosterone antagonists, were similar amongst the groups. These results were all in concordance with previous observations.

Endocan levels were significantly lower in patients with cirrhotic cardiomyopathy compared to the rest of the cohort $(5.6 v s .7 \mathrm{ng} / \mathrm{mL}, \mathrm{p}=0.034$, 
Fig. 2). The calculated AUROC was 0.64 (95\% CI $0.517-0.763)$ and at the cut-off value of $5 \mathrm{ng} / \mathrm{mL}$ endocan had $76 \%$ sensitivity and $43 \%$ specificity for diagnosing cirrhotic cardiomyopathy in this group (Fig. 3).

NT-proBNP levels did not differ according to the presence of cirrhotic cardiomyopathy $(\mathrm{p}=0.069$, Mann Whitney $U$ ) but higher levels correlated with increased serum endocan levels (Spearman's $\mathrm{r}=$ $0.27, \mathrm{p}=0.015)$. Mean arterial pressures, use of betablockers or aldosterone antagonists and QTc intervals were similar between groups and did not influence outcome.

Endocan levels were increased in patients with decompensated compared to compensated cirrhosis $(8.4 \mathrm{ng} / \mathrm{mL}$ vs. $4.3 \mathrm{ng} / \mathrm{mL}, \mathrm{p}<0.001$; Fig. 4). Endocan could differentiate between compensated cirrhosis (Child-Pugh class A) and, respectively decompensated cirrhosis (classes $\mathrm{B}$ and $\mathrm{C}$ ), with fair accuracy (AUROC $=0.756,95 \%$ CI 0.653-0.860). There was also a significant correlation between endocan levels and MELD scores in this population (Spearman's $\mathrm{r}=0.435, \mathrm{p}<001$ ).

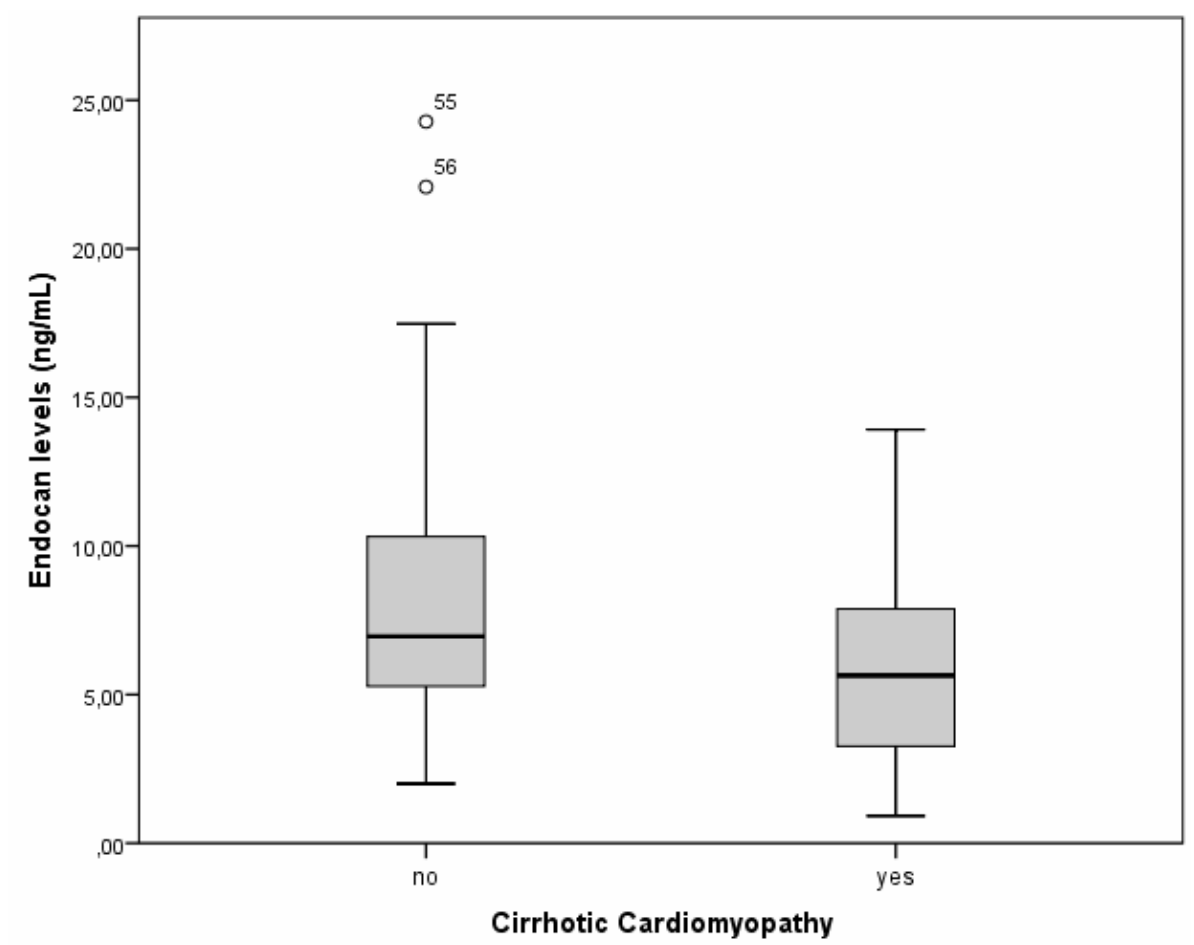

Endocan levels were lower in patients who fulfilled the consensus criteria for cirrhotic cardiomyopathy (5.6 vs. $7 \mathrm{ng} / \mathrm{mL}, \mathrm{p}=0.034$, Mann Whitney $U)$.

Figure 2. Serum endocan levels in patients with and without cirrhotic cardiomyopathy.

Table 2

Comparison of parameters between patients with and without cirrhotic cardiomyopathy

\begin{tabular}{|l|c|c|c|}
\hline & $\begin{array}{c}\text { No cirrhotic } \\
\text { cardiomyopathy }(\mathbf{n = 5 1})\end{array}$ & $\begin{array}{c}\text { Cirrhotic cardiomyopathy } \\
(\mathbf{n = 3 2})\end{array}$ & P value \\
\hline E/A & $0.98(0.48-1.8)$ & $0.8(0.58-1.74)$ & $\mathbf{0 . 0 1 5}^{*}$ \\
\hline IVRT (ms) & $77(40-135)$ & $77.5(16-155)$ & 0.758 \\
\hline DT (ms) & $213(114-496)$ & $243(148-408)$ & $\mathbf{0 . 0 3 2}^{*}$ \\
\hline LAV (mL/m $\left.{ }^{2}\right)$ & $34.9(10-60.5)$ & $23.8(8.9-60)$ & $\mathbf{0 . 0 1 2}$ \\
\hline E' (cm/s) & $9.76(3.8-16.6)$ & $8.2(3.6-12)$ & $\mathbf{0 . 0 3 5}^{*}$ \\
\hline LVEF (\%) & $64(56-80)$ & $51(35-75)$ & $<\mathbf{0 . 0 0 1 *}$ \\
\hline QTc (ms) & $417(377-497)$ & $405(372-475)$ & 0.107 \\
\hline $\begin{array}{l}\text { NT-proBNP } \\
\text { (ng/mL) }\end{array}$ & $165.7(30.4-1026)$ & $125(12.5-878)$ & 0.069 \\
\hline Endocan (ng/mL) & $7(2-24.3)$ & $5.6(0.9-13.9)$ & $\mathbf{0 . 0 3 2 *}$ \\
\hline MELD score & $12(7-27)$ & $11(6-26)$ & 0.571 \\
\hline MAP (mmHg) & $90(60-113)$ & $93(73-123)$ & 0.116 \\
\hline
\end{tabular}

E/A - age-adjusted early-to-late peak diastolic mitral inflow velocity ratio; IVRT - isovolumetric relaxation time of the left ventricle; DT - deceleration time of the E wave; LAV - 
Left atrial volume indexed to the body-surface area; E' - lateral early diastolic mitral annular velocity; LVEF - left ventricular ejection fraction; QTc - rate-adjusted QT interval; NT proBNP - aminoterminal pro-brain natriuretic peptide; MELD - Model for end-stage liver disease; MAP - mean arterial pressure

*- statistically significant using Mann Whitney U

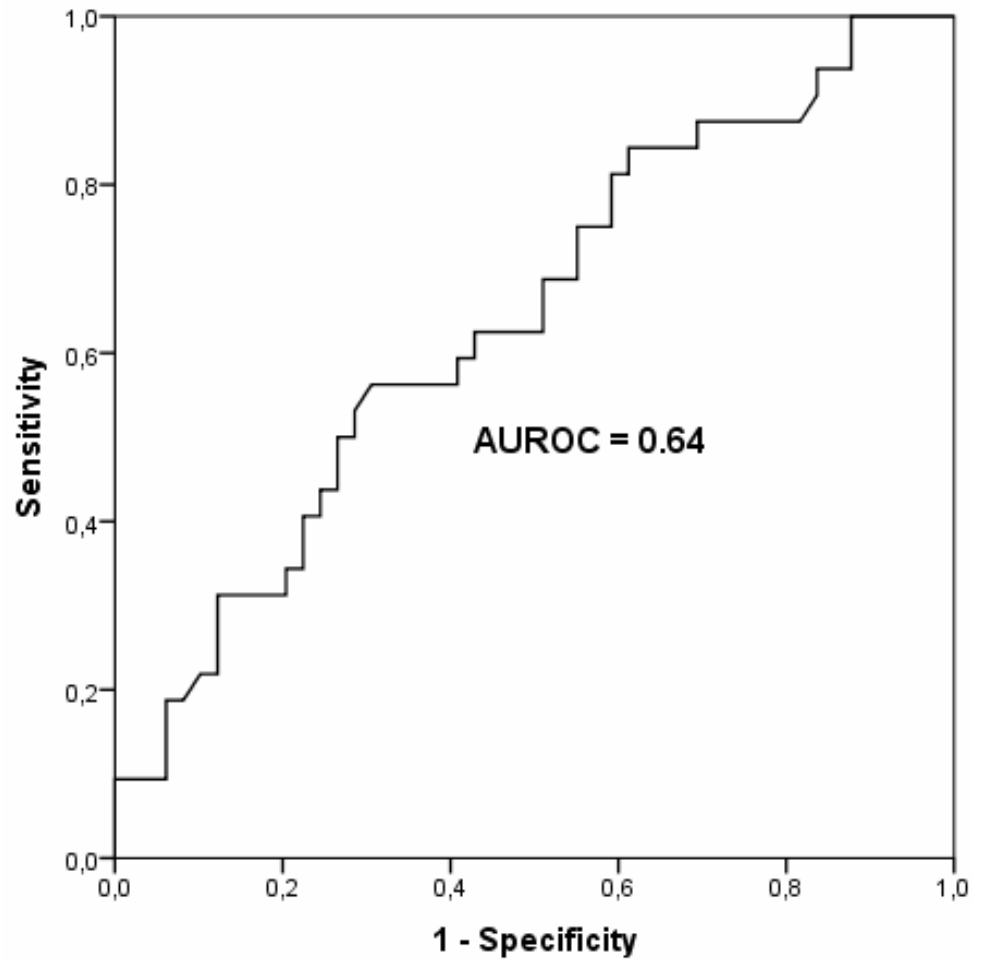

Figure 3. AUROC curve for cirrhotic cardiomyopathy diagnosis.

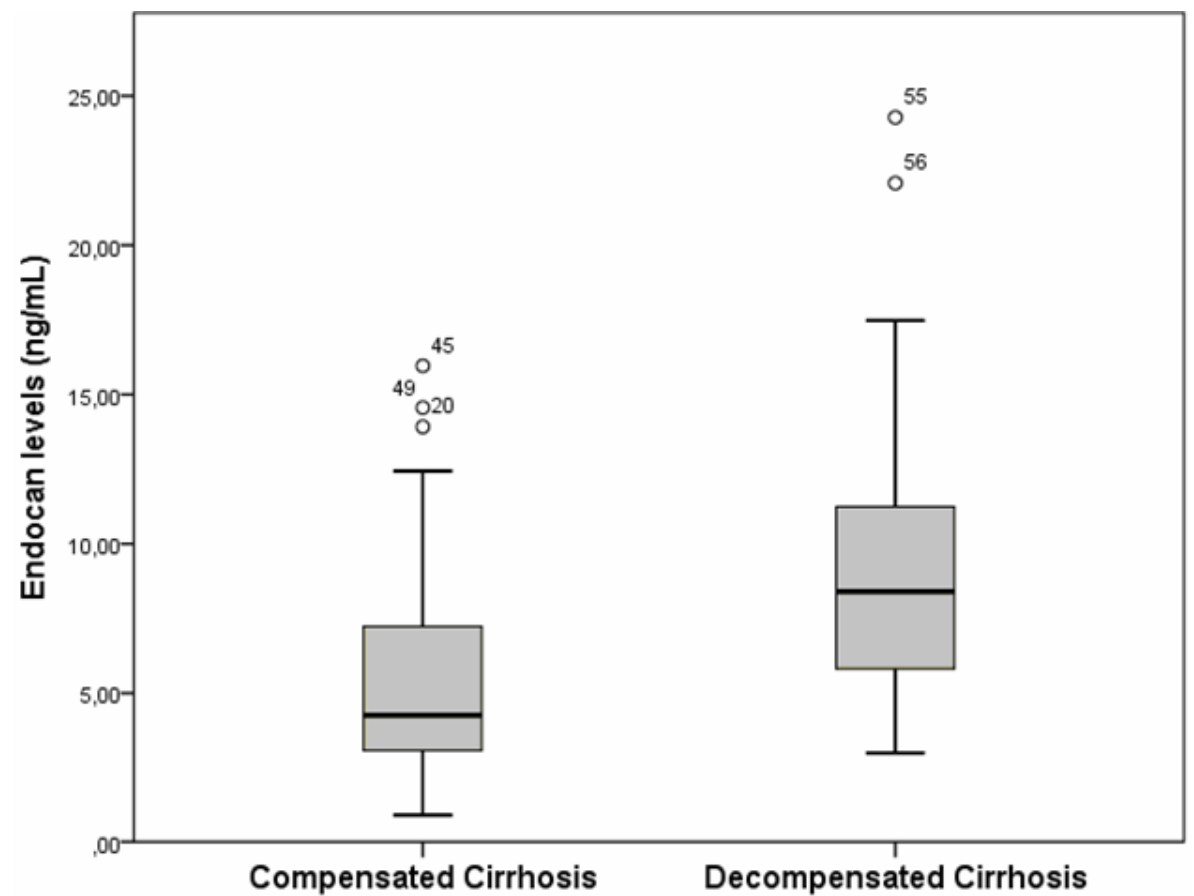

Endocan was significantly increased in patients with decompensated cirrhosis defined by advanced Child Pugh class $(\mathrm{B} / \mathrm{C})$ compared to patients with compensated liver disease (Child class A): $8.4 \mathrm{ng} / \mathrm{mL} v s .4 .3 \mathrm{ng} / \mathrm{mL}, \mathrm{p}<0.001$, Mann Whitney $U$.

Figure 4. Endocan levels according to severity of liver cirrhosis. 


\section{Follow-up}

During the study period 5 patients were lost to follow-up and 1 received a liver transplant. There were 17 deaths and 51 patients suffered at least one disease-related event: 24 developed ascites, 2 hepatorenal syndrome, 9 severe infections, 10 had severe haemorrhagic events, 17 presented with encephalopathy and 3 were diagnosed with hepatocellular carcinoma. Of the 44 patients with compensated liver disease (Child class A) 20 experienced decompensations and 5 died, while 29 patients with decompensated liver disease at enrollment had further decompensations and 12 of them died during the follow-up period. Patients with more advanced liver disease (Child classes B and C) had shorter survival times compared to patients with compensated cirrhosis $(p=0.012$ Mantel-Cox). Cirrhotic cardiomyopathy was not a risk factor for death $\left(\mathrm{p}=0.26, \chi^{2}\right)$ or development of cirrhotic-related complications $\left(\mathrm{p}=1, \chi^{2}\right)$.

Patients with endocan levels above $5 \mathrm{ng} / \mathrm{mL}$ had a higher mortality rate than patients with lower values (OR 4.5 95\% CI 1.06-31.1) in univariate analysis. However, this effect did not hold up in multivariate analysis after adjusting for age, gender and severity of cirrhosis in binary logistic regression when only decompensated cirrhosis correlated whith risk of death (OR 3.04 95\% CI 1.04-8.92). Transplantfree survival time was significantly shorter in the group with higher endocan levels $(\mathrm{p}=0.045 \mathrm{log}$ rank Mantel-Cox, Fig. 5 - panel A). Adverse event rates were similar between the two groups $(37 / 56$ vs. $12 / 27, \mathrm{p}=0.09 \chi^{2}$ ), however endocan levels above $5 \mathrm{ng} / \mathrm{mL}$ correlated with shorter time to first liver-related adverse event ( $\mathrm{p}=0.031$ Mantel Cox, Fig. 5 - panel B). All three patients who developed hepatocellular carcinoma during the study had endocan levels above $5 \mathrm{ng} / \mathrm{mL}$ at enrollment.

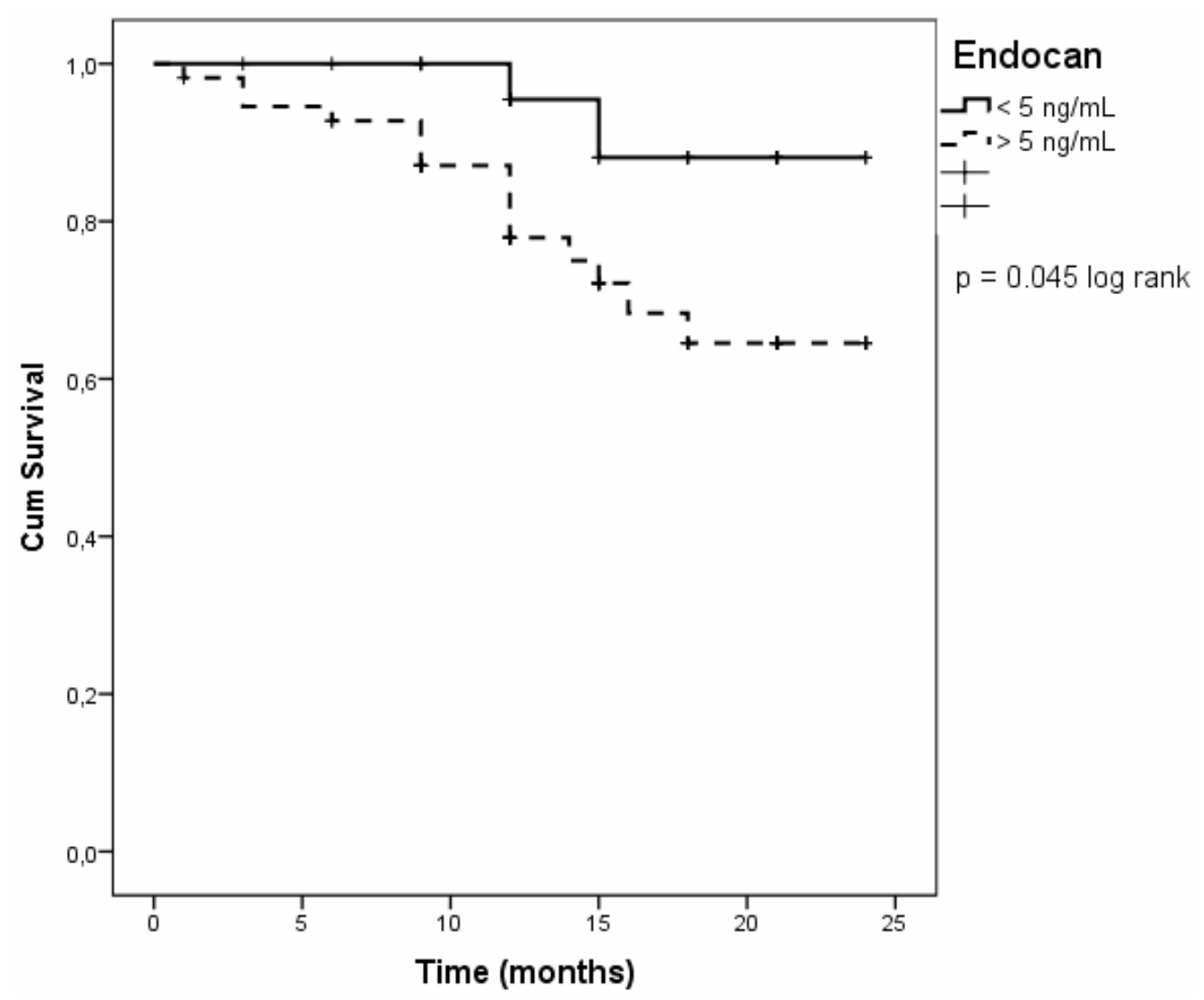

The Kaplan Meier survival curve shows higher mortality during the follow-up for patients with serum endocan levels above $5 \mathrm{ng} / \mathrm{mL}$ (OR 4.5 95\% CI 1.06-31.1).

Figure 5, panel A. Patient survival stratified according to endocan levels. 


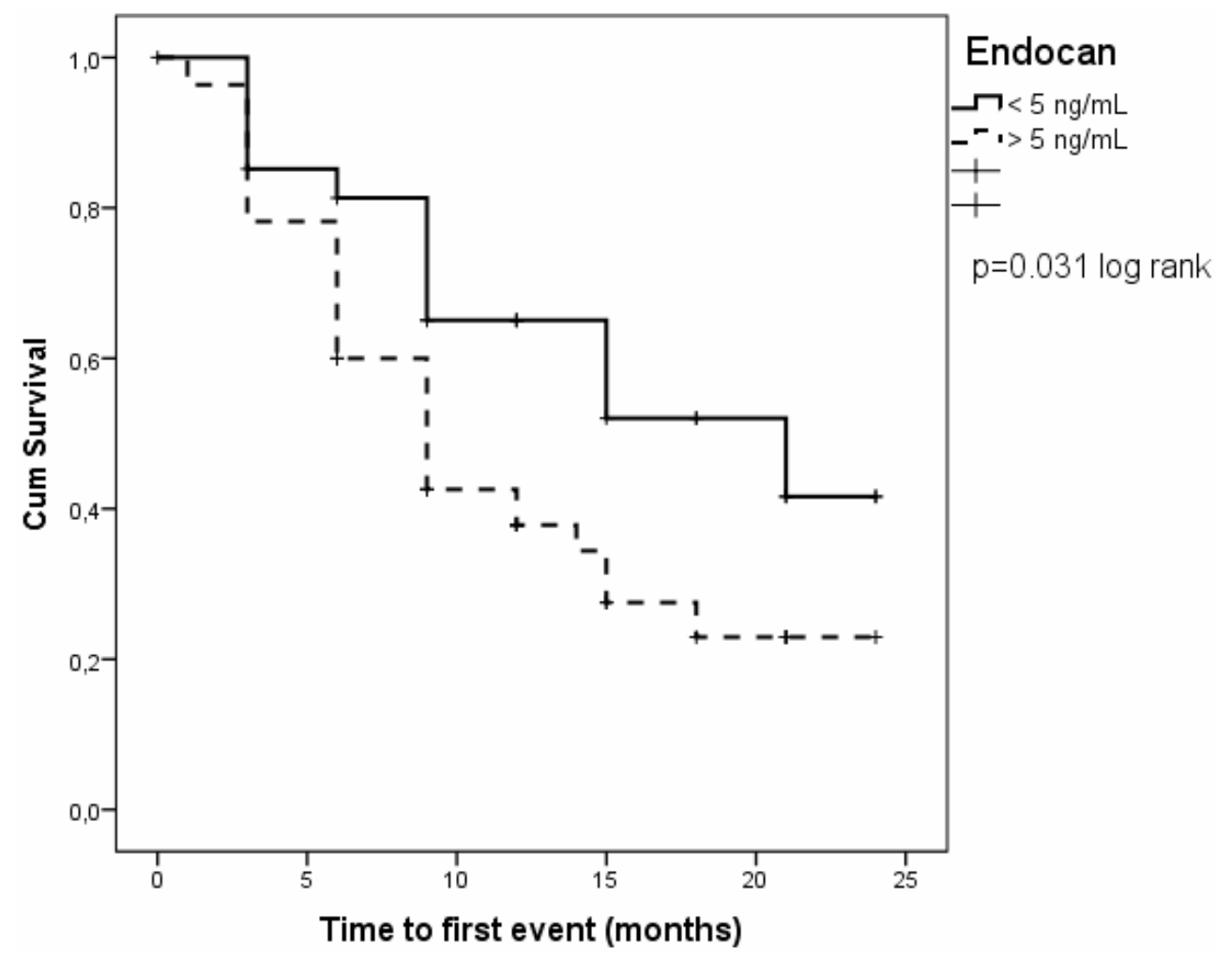

The Kaplan Meier curve shows that patients with endocan levels above $5 \mathrm{ng} / \mathrm{mL}$ had a decreased time until they developed the first liver-related adverse event during the follow-up period $(\mathrm{p}=0.031$ Mantel Cox).

Figure 5, panel B. Time to development of first decompensation of cirrhosis according to endocan levels.

\section{DISCUSSION}

This is a prospective follow-up study of a cohort of cirrhotic patients that reports on the utility of endocan in assessing cirrhotic cardiomyopathy and its outcome. In this population serum endocan levels were decreased in the presence of cirrhotic cardiomyopathy while higher values correlated with the severity of cirrhosis and outcome. Levels of endocan above the threshold of $5 \mathrm{ng} / \mathrm{mL}$ predicted shorter time to decompensation or liverrelated death. To our knowledge this is the first report of endocan in the setting of cirrhotic cardiomyopathy.

Endocan is a promising serum biomarker that has gained a lot of attention recently due to its role in inflammatory and vascular regulatory pathways. Various molecules such as endotoxin, endocannabinoids, endothelin-1, TNF $\alpha$ and vascular endothelial growth factors have been studied in cirrhosis with reports showing a profound alteration in their expression in both experimental and real-life settings. However, this abundance of promising molecules available has not yet translated into useful clinical tools and there is a lack of robust biomarkers validated in follow-up studies.

Based on reports of its prognostic role in inflammatory disorders, cardiovascular disease, nonalcoholic liver disease [25] and hepatocellular carcinoma we hypothesized that endocan levels would correlate with the presence of cirrhotic cardiomyopathy and predict unfavourable outcome. There have been many attempts to identify relevant biomarkers of cardiovascular dysfunction [26] in cirrhosis in order to improve the diagnostic workup and management of this complication. Episodes of transient bacteremia or endotoxemia which are common in cirrhosis entertain a proinflammatory state and Karagiannakis and his group [27] have shown that bacterial translocation correlates with diastolic dysfunction. Endocan seems to be upregulated in response to TNF- $\alpha$ and lipopolysaccharide-binding protein [28] and recent studies shine a light on its role in atherosclerosis and the link between inflammation and endothelial dysfunction. This would suggest that endocan expression is increased in the setting of cirrhotic cardiac dysfunction, but our results have shown significantly 
lower endocan levels in patients fulfilling the consensus criteria for cirrhotic cardiomyopathy. A possible explanation for our contrary finding is the recent observation that endocan levels are significantly lower in patients with essential hypertension [29]. It is thus plausible that although endocan levels are increased in cirrhotic patients compared to controls, patients with more pronounced cardiovascular dysfunction leading to reduced systemic vascular resistance and lower arterial blood pressure might show lower levels of endocan.

While the hyperdynamic circulation in cirrhosis is well documented, cirrhotic cardiomyopathy is a relatively new entity of uncertain clinical impact and that has to be fully characterized yet. The only diagnostic criteria proposed so far are based on a consensus definition which mainly requires echocardiographic evidence of diastolic and systolic dysfunction and exclusion of other causes of heart disease. These parameters have been criticized for low accuracy in describing cardiac function as newer techniques like tissue-Doppler and strain imaging are increasingly being used by cardiologists to reliably diagnose diastolic and systolic dysfunction. These techniques may be better suited to minimize confounding factors such as the influence of pre- or afterload on heart function but they are also imperfect tools and operator-dependent [30]. In a previous report as well as in this study we have found a good concordance between definitions of cirrhotic cardiomyopathy based on pulsed-wave and tissueDoppler imaging assessment, but elucidation of the best diagnostic algorithm for this entity is eagerly awaited. We decided to adhere to the Montreal definition of cirrhotic cardiomyopathy and have interestingly noticed a significant overlap between groups where NT-proBNP and left atrial volume were concerned. This finding reinforces the need to further test and refine the diagnostic criteria and makes forays into cardiac dysfunction in cirrhotic patients all the more vital.

In their study Toshikuni and his group [11] concluded that endocan might be an independent survival predictor for patients with cirrhosis. Our results also favour a role for endocan as a prognostic marker for worse outcome in cirrhosis. Predicting decompensation and survival is the purpose for widely employed predictive scores such as Child and MELD. Assessing the degree of liver dysfunction is complicated and invariably each score has weaknesses. Decisional bodies have recognized the need to improve the waiting list allocation methodology through the granting of exception points for aspects not included in the scoring criteria and, recently, the UNOS changed their policy to include serum sodium in the MELD score. In this setting of limited access to liver transplantation, introducing novel and accurate biomarkers in riskassessment models is needed to further refine prioritization policies.

We have found that cirrhotic patients have significantly higher endocan levels than controls and this may reflect the severe intrahepatic endothelial dysfunction described in cirrhosis. The results also strongly suggest a link between endocan and severity of cirrhosis as assessed by MELD score or Child class. Furthermore, while they did not have more adverse events patients with higher endocan levels decompensated earlier and had a significantly higher risk of death during the follow-up. Since endocan levels are increased by inflammation and angiogenesis, both of which are progressively and severely altered in cirrhosis, these findings confirm our initial hypothesis and underline the prognostic potential of this new biomarker. Endocan predicted mortality in univariate analysis but the effect was lost when accounting for severity of cirrhosis as assessed by Child class.

This study is the first to investigate the link between endocan and the presence of cardiac dysfunction in cirrhosis. Its follow-up design allowed us to draw valid conclusions regarding the clinical significance of the correlations we have found. However, it also has several flaws. It is a singlecenter study with a limited sample size that made it impossible to assess the relationship between endocan levels and particular complications such as hepatocellular carcinoma and this should be addressed in larger trials. The median follow-up was adequate to identify a strong effect on outcome in a population with a predictibly high rate of events, but it is possible that a longer follow-up could have modified our findings. Also we have only tested endocan and NT-proBNP levels whereas additional markers of cardiovascular dysfunction or inflammation as well as a more comprehensive investigation of haemodynamic parameters would have allowed for a better assessement of our findings. Multicenter studies designed to include echocardiographic examinations at various follow-up visits may further improve our understanding of the role of cirrhotic cardiomyopathy on the outcome of patients with cirrhosis.

In conclusion, in this prospective cohort study we report a promising link between decreased levels 
of endocan and the presence of cirrhotic cardiomyopathy. Cirrhotic cardiomyopathy was frequent in this study population but was not correlated with adverse outcome on follow-up. Patients with endocan levels above $5 \mathrm{ng} / \mathrm{mL}$ decompensated earlier and had shorter transplant-free survival times.

Abbreviations: CCM - cirrhotic cardiomyopathy; NT-pro BNP - aminoterminal pro-brain natriuretic peptide; MELD Model for end-stage liver disease; E/A - age-adjusted early-to-late peak diastolic mitral inflow velocity ratio; IVRT - isovolumetric relaxation time of the left ventricle; DT - deceleration time of the E wave; LAV- Left atrial volume indexed to the bodysurface area; E' - lateral early diastolic mitral annular velocity.

Acknowledgement: Part of data presented in this manuscript were previously presented in a poster presentation at the International Liver Congress 2017-52nd Annual Meeting of the European Association for the Study of Liver, Amsterdam, 19-23 April 2017.

Conflict of interest: The authors declare that there is no conflict of interest.

Financial support: The work was partly supported by the "Carol Davila" School of Medicine Young Researcher Grant (28339/2013) received by Theodor Voiosu.

Introducere. Scopul studiului a fost de a analiza relația dintre endocan şi cardiomiopatia cirotică.

Materiale şi metode. Au fost incluşi în studiul prospectiv pacienți cu ciroză hepatică, dar fără boală cardiacă având ca efecte urmărite decompensarea cirozei sau moartea.

Rezultate. Au fost incluşi 83 de pacienți cu ciroză din care 32 aveau cardiomiopatie cirotică. Nivelurile serice ale endocanului au fost semnificativ statistic mai mici la pacienții cu cardiomiopatie cirotică (5.6 vs. $7 \mathrm{ng} / \mathrm{mL}, p=0.034$ ). Endocanul seric s-a corelat cu severitatea cirozei, cu timpul scurs până la decompensare sau până la moartea de cauză hepatică (OR 4.5 95\% CI 1.06-31.1).

Concluzii. Endocanul este un biomarker promițător al severității cirozei şi poate ajuta pentru diagnosticul disfuncției cardiace în cadrul acestei populații.

Correspondence to: Andrei Voiosu, MD, PhD, Gastroenterology Department,

Spitalul Clinic Colentina, Şos. Ştefan cel Mare 19-21, 021025, Bucharest, Romania

E-mail: andreivoiosu@yahoo.com

\section{REFERENCES}

1. SEO K, KITAZAWA T, YOSHINO Y, et al. Characteristics of serum endocan levels in infection. PLoS One. 2015; 10(4):e0123358.

2. COX LA, VAN EIJK LT, RAMAKERS BP, et al. Inflammation-induced increases in plasma endocan levels are associated with endothelial dysfunction in humans in vivo. Shock. 2015; 43(4):322-326.

3. SCHERPEREEL A, DEPONTIEU F, GRIGORIU B, et al. Endocan, a new endothelial marker in human sepsis. Crit Care Med.2006; 34(2):532-537.

4. PALUD A, PARMENTIER-DECRUCQ E, PASTRE J, et al. Evaluation of endothelial biomarkers as predictors of organ failures in septic shock patients. Cytokine. 2015; 73(2):213-218.

5. YANG J, YANG Q, YU S, et al. Endocan: A new marker for cancer and a target for cancer therapy. Biomed Rep. 2015; 3(3):279-283.

6. BALTA S, MIKHAILIDIS DP, DEMIRKOL S, et al. Endocan: A novel inflammatory indicator in cardiovascular disease? Atherosclerosis.2015; 243(1):339-343.

7. HUANG GW, TAO YM, DING X. Endocan expression correlated with poor survival in human hepatocellular carcinoma. Dig Dis Sci. 2009; 54(2):389-394.

8. NAULT JC, GUYOT E, LAGUILLIER C, et al. Serum proteoglycans as prognostic biomarkers of hepatocellular carcinoma in patients with alcoholic cirrhosis. Cancer Epidemiol Biomarkers Prev.2013; 22(8):1343-1352.

9. OZAKI K, TOSHIKUNI N, GEORGE J, et al. Serum endocan as a novel prognostic biomarker in patients with hepatocellular carcinoma. J Cancer. 2014; 5(3):221-230.

10. TOK D, EKIZ F, BASAR O, et al. Serum endocan levels in patients with chronic liver disease. Int J Clin Exp Med. 2014; 7(7):1802-1807.

11. TOSHIKUNI N, OZAKI K, GEORGE J, et al. Serum endocan as a survival predictor for patients with liver cirrhosis. Can J Gastroenterol Hepatol. 2015; 29(8):427-430.

12. MØLLER S, HENRIKSEN J.H. Cardiovascular complications of cirrhosis. Gut. 2008; 57:268-278.

13. GOLDBERG, DS, FALLON MB. The Art and Science of Diagnosing and Treating Lung and Heart Disease Secondary to Liver Disease. Clin Gastroenterol Hepatol. 2015; 13(12):2118-2127. 
14. LOPEZ-TALAVERA JC, CADELINA G, OLCHOWSKI J, et al. Thalidomide inhibits tumor necrosis factor alpha, decreases nitric oxide synthesis, and ameliorates the hyperdynamic circulatory syndrome in portal-hypertensive rats. Hepatology. 2016; 23:1616-1621.

15. KUDDUS RH, NALESNIK MA, SUBBOTIN VM, et al. Enhanced synthesis and reduced metabolism of endothelin-1 (ET-1) by hepatocytes--an important mechanism of increased endogenous levels of ET-1 in liver cirrhosis. J Hepatol. 2000; 33(5):725-732.

16. BALDASSARRE M, GIANNONE FA, NAPOLI L, et al. The endocannabinoid system in advanced liver cirrhosis: pathophysiological implication and future perspectives. Liver Int. 2013; 33:1298-1308.

17. BUSK TM, BENDTSEN F, NIELSEN HJ, et al. TIMP-1 in patients with cirrhosis: relation to liver dysfunction, portal hypertension, and hemodynamic changes. Scand J Gastroenterol.2014; 49(9):1103-1110.

18. MORTENSEN C, JENSEN JS, HOBOLTH L, et al. Association of markers of bacterial translocation with immune activation in decompensated cirrhosis. Eur J Gastroenterol Hepatol.2016; 26(12):1360-6.

19. WIEST R, LAWSON M, GEUKING M. Pathological bacterial translocation in liver cirrhosis. J Hepatol. 2014; 60(1):197-209.

20. GASKARI SA, LIU H, D'MELLO C, et al. Blunted cardiac response to hemorrhage in cirrhotic rats is mediated by local macrophage-released endocannabinoids. J Hepatol.2015; 62(6):1272-7.

21. VOIOSU AM, DAHA IC, VOIOSU TA, et al. Prevalence and impact on survival of hepatopulmonary syndrome and cirrhotic cardiomyopathy in a cohort of cirrhotic patients. Liver Int. 2015; 35(12):2547-2555.

22. NAGUEH SF, APPLETON CP, GILLEBERT TC, et al. Recommendations for the evaluation of left ventricular diastolic function by echocardiography. J Am Soc Echocardiogr. 2009; 22:107-133.

23. VOIOSU T, BALANESCU P, BENGUS A, et al. Serum endocan levels are increased in patients with inflammatory bowel disease. Clin Lab.2014; 60(3):505-510.

24. BĂLĂNESCU P, LADARU A, BĂLĂNESCU E, et al. Endocan, Novel Potential Biomarker for Systemic Sclerosis: Results of a Pilot Study. J Clin Lab Anal. 2016; 30(5):368-373.

25. DALliO M, MASARONE M, CAPRIO GG, et al. Endocan Serum Levels in Patients with Non-Alcoholic Fatty Liver Disease with or without Type 2 Diabetes Mellitus: A Pilot Study. J Gastrointestin Liver Dis. 2017; 26(3):261-268.

26. WIESE S, MORTENSEN C, GØTZE JP, et al Cardiac and proinflammatory markers predict prognosis in cirrhosis. Liver Int. 2014; 34(6):e19-30.

27. KARAGIANNAKIS DS, VLACHOGIANNAKOS J, ANASTASIADIS G, et al. Frequency and severity of cirrhotic cardiomyopathy and its possible relationship with bacterial endotoxemia. Dig Dis Sci. 2013; 58(10):3029-3036.

28. LEE W, KU SK, KIM SW, et al. Endocan elicits severe vascular inflammatory responses in vitro and in vivo. J Cell Physiol. 2014; 229(5):620-630.

29. BALTA S, MIKHAILIDIS DP, DEMIRKOL S, et al. Endocan--a novel inflammatory indicator in newly diagnosed patients with hypertension: a pilot study. Angiology. 2014; 65(9):773-777.

30. TSCHÖPE C, PAULUS WJ. Doppler echocardiography yields dubious estimates of left ventricular diastolic pressures. Circulation. 2009; 120: 810-820.

Received February 8, 2018 